\title{
Clinical characteristics of pediatric pertussis cases, Quebec 2015-2017
}

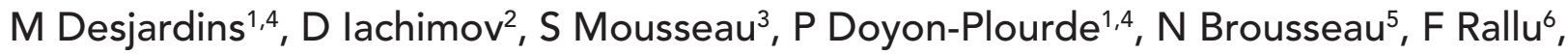 \\ C Quach ${ }^{1,4,6,7,8 *}$
}

\section{Abstract}

Background: The introduction of the acellular pertussis vaccine may have changed the epidemiological and clinical features of pertussis in Canadian children.

Objective: To describe the demographics, clinical presentation and outcomes of children and adolescents with pertussis presenting to a tertiary care hospital.

Methods: Retrospective cohort of consecutive patients evaluated at the Centre Hospitalier Universitaire Sainte-Justine (CHUSJ) and tested with a bacterial multiplex real-time polymerase chain reaction (PCR) for Bordetella pertussis or B. parapertussis between June 2015 and March 2017. Demographics, clinical presentations and outcomes were described for positive test results. The Modified Preziosi Scale was used to assess disease severity; severe disease was defined as a score $\geq 7$.

Results: The age distribution of the 144 positive patients with a clinical encounter at CHUSJ was as follows: less than three months $(n=25 / 144,17.4 \%)$, four months to nine years ( $n=63 / 144$, $43.8 \%$ ) and 10 to 18 years $(n=56 / 144,38.9 \%)$. The most common symptoms at presentation were paroxysmal cough (70.1\%), post-tussive emesis (47.2\%) and coryza (33.3\%). Over $84.0 \%$ of cases in infants less than three months of age had severe pertussis $(92.0 \%$ required hospitalization and $28.0 \%$ intensive care admission). In children four months to nine years of age, $22.2 \%$ had severe pertussis and $11.1 \%$ required hospitalization. Only two (3.6\%) children greater than 10 years had severe disease.

Conclusion: Pertussis still affects children of all ages in Quebec. In older children, it tends to be a milder disease. When it affects infants, who do not yet have full protection from pertussis vaccination, it often causes severe disease, especially in those less than three months of age. This evidence further supports the implementation of a pertussis vaccination program in pregnant women.

Suggested citation: Desjardins M, lachimov D, Mousseau S, Doyon-Plourde P, Brousseau N, Rallu F, Quach C. Clinical characteristics of pediatric pertussis cases, Quebec 2015-2017. Can Commun Dis Rep 2018;44(9):190-5. https://doi.org/10.14745/ccdr.v44i09a01

Keywords: pertussis, pediatric, symptoms, outcomes, Quebec

\author{
Affiliations \\ ${ }^{1}$ Medical Microbiology and \\ Infectious Diseases, Centre \\ Hospitalier de I'Université de \\ Montréal, Montréal, QC \\ ${ }^{2}$ Research Institute, Centre \\ Hospitalier Universitaire \\ Sainte-Justine, Montréal, QC \\ ${ }^{3}$ Pediatric Emergency Division, \\ Department of Pediatrics, \\ Centre Hospitalier Universitaire \\ Sainte-Justine, Montréal, QC \\ ${ }^{4}$ Department of Microbiology, \\ Infectious Diseases, and \\ Immunology, Faculty of Medicine, \\ University of Montreal, Montréal, \\ QC \\ ${ }^{5}$ Biological Risks and \\ Occupational Health Division, \\ Institut national de santé publique \\ du Québec, Québec, QC \\ ${ }^{6}$ Department of Medical \\ Microbiology, Centre Hospitalier \\ Universitaire Sainte-Justine, \\ Montréal, QC \\ ${ }^{7}$ Infection Prevention \& Control, \\ Centre Hospitalier Universitaire \\ Sainte-Justine, Montréal, QC \\ ${ }^{8}$ Chair, National Advisory \\ Committee on Immunization
}

*Correspondence: c.quach@ umontreal.ca

\section{Introduction}

Pertussis, or whooping cough, is a respiratory tract infection caused by Bordetella pertussis and B. parapertussis. Infected patients may display a wide range of symptoms depending on age, immunization status and coinfections, often making pertussis difficult to diagnose $(1,2)$.

Pertussis is a vaccine-preventable disease. Vaccination against pertussis with a whole cell vaccine, which was introduced in Canada in 1943, led to a significant decrease in the disease incidence (3). The whole cell vaccine was replaced with the acellular pertussis vaccine in the late 1990s to decrease the incidence of adverse events following immunization.
The pertussis-containing vaccine is currently administered at two, four, six and 18 months of age with a booster between four and six years of age. In Quebec, the universal acellular vaccination program was introduced in 1998 with a marked impact on pertussis incidence (4-6). In 2016, despite vaccination coverage of $97.3 \%$ in children at one year of age (7), the incidence of pertussis in those less than 18 years of age was still 60 cases per 100,000 children (8).

It has been shown that immunity and protection provided by the acellular vaccine wanes rapidly (9), and this may have changed the clinical presentation of pertussis in children. Young infants are particularly vulnerable to pertussis, possibly because those less than three months of age have only received 
one dose of pertussis vaccine, which provides only partial protection $(6,10,11)$. To address this, the National Advisory Committee on Immunization (NACl) evaluated the evidence on vaccination of pregnant women and found this to be highly effective in preventing pertussis in infants (12-14). In 2018, NACl recommended the immunization of pregnant women against pertussis (15), noting it could lead to a $90 \%$ reduction of the incidence of pertussis in infants born to vaccinated mothers (16).

The last hospital-based studies describing the epidemiological and clinical features of pertussis in Canadian children were conducted from 1991 to $2004(17,18)$; thus, the current burden of illness in children in Canada is currently unknown.

The objective of this study was to describe the clinical presentation and outcomes of children with pertussis who were evaluated between June 2015 and March 2017 at the Centre Hospitalier Universitaire Sainte-Justine (CHUSJ). This hospital is in Montréal (Quebec) and is the only free-standing children's hospital in the province of Quebec, with 80,000 emergency care visits annually (19).

\section{Methods}

\section{Study design}

This was a retrospective, observational cohort study of consecutive patients evaluated at CHUSJ for suspected pertussis. Children presenting for suspected pertussis were primarily from the hospital's catchment area and were assessed in the emergency department. Occasionally, children were tested for pertussis as inpatients. All children were tested with a bacterial multiplex polymerase chain reaction (PCR) (B. pertussis, $B$. parapertussis, B. holmesii, Mycoplasma pneumoniae and Chlamydophila pneumoniae). Since 2015, all suspected pertussis cases seen at CHUSJ are tested using this multiplex PCR.

Cases positive for $B$. pertussis or $B$. parapertussis between June 2015 and March 2017 were identified through the laboratory information system and clinical data were extracted using manual chart review. The study protocol was approved by the CHUSJ ethics committee.

\section{Study population}

The study included consecutive patients aged zero to 17 years, who had a positive multiplex PCR (cycle threshold [Ct] value less than 36 ) for $B$. pertussis or $B$. parapertussis, and whose clinical and laboratory data were available in the CHUSJ microbiology laboratory information system between June 2015 and March 2017. Since B. parapertussis may cause a disease similar to pertussis and the current vaccine against $B$. pertussis may offer cross-protection to $B$. parapertussis (20), patients with $B$. parapertussis-positive PCR were included in the study. Patients with equivocal PCR results (Ct values 36-39.9) were also included, as they are currently considered as pertussis cases by public health authorities in Quebec, if they present symptoms compatible with pertussis (6). Patients who tested positive for $B$. holmesii were not included, since this Bordetella species may cause a significant different disease (1). Patients 18 years and older, as well as patients without a clinical encounter at CHUSJ (e.g., samples received from other hospitals), were excluded.

\section{Data collection and analysis}

In addition to reviewing the laboratory data, manual chart reviews of electronic medical records were performed (using Chartmaxx; Quest Diagnostics, Secaucus, New Jersey, United States [US]), using standardized case report forms to collect information on 1) clinical presentation (using triage nurses' evaluation and physicians' clinical notes on the day the PCR was ordered), 2) investigation results and 3) outcomes (hospitalization, length of stay, macrolide treatment, intensive care admission or death). Data collection was performed by two members of the research team (MD, DI) and 10\% of the charts were reviewed by both researchers to evaluate inter-rater agreement (tested using kappa statistics). Patients were divided in three age groups, as suggested at the Global Pertussis Initiative roundtable meeting held in February 2011 (21): less than or equal to three months; four months to nine years; and 10 to 18 years of age. Absolute numbers and proportions were used to analyze demographics, clinical presentations and outcomes. Interquartile range (IQR) was used to evaluate the statistical dispersion of continuous variables. The Modified Preziosi Scale (MPS) (22) was used to assess disease severity. Severe pertussis was defined by MPS score greater or equal to seven $(23,24)$. Microsoft Excel 2016 (Redmond, Washington, US) was used to generate proportions and IQR. Statistical analyses were descriptive.

\section{Results}

Of the 1,526 multiplex PCR tests performed between June 11, 2015 and March 31, 2017, 173 patients were positive or equivocal for $B$. pertussis or $B$. parapertussis (11.3\% positivity). Twenty-nine patients were excluded: two were 18 years or older and 27 did not have a clinical encounter at CHUSJ.

\section{Demographics}

A total of 144 patients were analyzed: 133 B. pertussis cases (109 positive, 24 equivocal); and 11 B. parapertussis cases (seven positive, four equivocal) (Table 1). Patients were pooled together for analysis because of the small number of patients who tested

\section{Table 1: Characteristics of children with PCR-confirmed pertussis}

\begin{tabular}{|c|c|c|c|c|}
\hline \multirow[b]{2}{*}{ Characteristics } & \multicolumn{4}{|c|}{ Age groups, n (\%) } \\
\hline & $0-3 \mathrm{mos}$ & $\begin{array}{c}4 \mathrm{mos}-9 \\
\mathrm{yrs}\end{array}$ & $10-18$ yrs & Total \\
\hline Laboratory result & $25(17.4)$ & $63(43.8)$ & $56(38.9)$ & $144(100.0)$ \\
\hline $\begin{array}{l}\text { B. pertussis } \\
\text { positive }\end{array}$ & $19(76.0)$ & $45(71.4)$ & $45(80.4)$ & $109(75.7)$ \\
\hline $\begin{array}{l}\text { B. parapertussis } \\
\text { positive }\end{array}$ & $1(4.0)$ & $5(7.9)$ & $1(1.8)$ & $7(4.9)$ \\
\hline $\begin{array}{l}\text { B. pertussis } \\
\text { equivocal }\end{array}$ & $5(20.0)$ & $9(14.3)$ & $10(17.9)$ & $24(16.7)$ \\
\hline $\begin{array}{l}\text { B. parapertussis } \\
\text { equivocal }\end{array}$ & $0(0.0)$ & $4(6.3)$ & $0(0.0)$ & $4(2.0)$ \\
\hline Female & $14(56.0)$ & $33(52.4)$ & 35 (62.5) & $82(56.9)$ \\
\hline \multicolumn{5}{|l|}{ Past medical history } \\
\hline Asthma & $0(0.0)$ & $11(17.5)$ & $11(19.6)$ & $22(15.3)$ \\
\hline $\begin{array}{l}\text { Immunization } \\
\text { status up to date }\end{array}$ & $22(88.0)$ & $42(66.7)$ & $48(85.7)$ & $112(77.8)$ \\
\hline Prematurity & $4(16.0)$ & $4(6.3)$ & $1(1.8)$ & $9(6.3)$ \\
\hline
\end{tabular}


positive for $B$. parapertussis and because both bacteria cause similar respiratory syndromes.

Among the 144 children, 25 (17.4\%) were less than three months old, $63(43.8 \%)$ were between four months and nine years and $56(38.9 \%)$ were between 10 and 18 years. The proportion of positive tests increased with age, reaching a peak of $35-45 \%$ in adolescents 10 to 15 years old (Figure 1 ).

Figure 1: Distribution of patients with positive pertussis PCR per age $(n=144)$

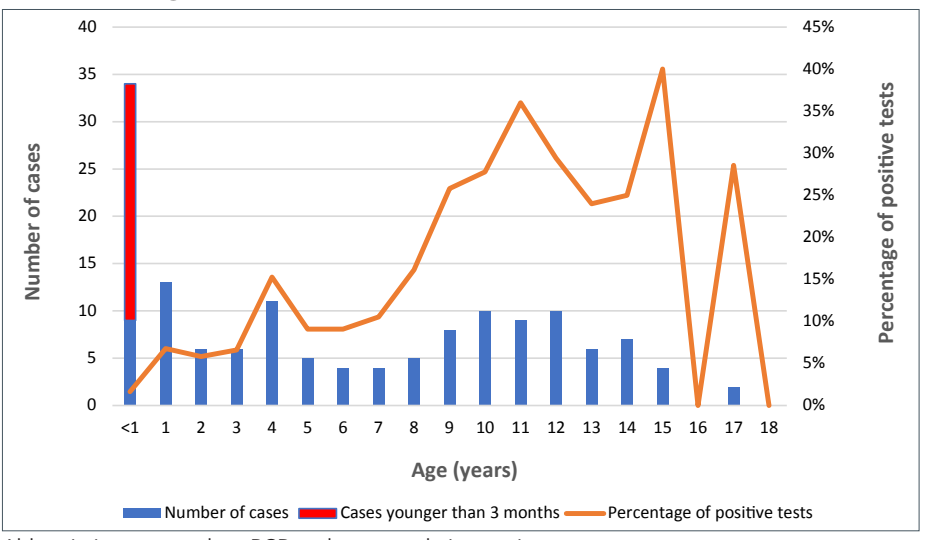

Abbreviations: $n$, number; $\mathrm{PCR}$, polymerase chain reaction

Pertussis was reported all year round (Figure 2).

Figure 2: Distribution of patients with positive pertussis PCR during the study period $(n=144)$

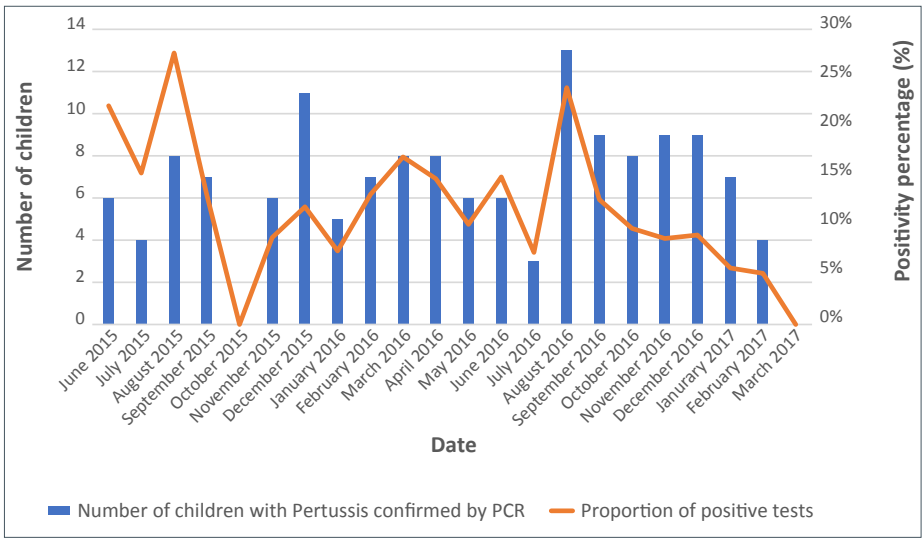

Abbreviations: $n$, number; $\mathrm{PCR}$, polymerase chain reaction

\section{Clinical presentation}

The most common symptoms at presentation were paroxysmal cough $(70.1 \%)$, post-tussive emesis $(47.2 \%)$ and coryza (33.3\%) (Table 2). From the 100 chest X-rays performed $(69.4 \%$ of all cases), only eight (8.0\%) were consistent with pneumonia.

The 25 children under the age of three months were the most severely affected by pertussis, with a median MPS score of 12 (interquartile range [IQR]: 9-15). The disease was considered severe in $84.0 \%$ of children less than three months of age. All 10 reported cases of apnea, $75.0 \%(n=15 / 20)$ of cases with cyanosis, $76.9 \%(n=10 / 13)$ of cases with chest retractions and $45 \%$ $(n=9 / 20)$ of cases with inspiratory whoop were in this age group.
Table 2: Clinical presentation and paraclinical tests of children with PCR-confirmed pertussis

\begin{tabular}{|c|c|c|c|c|}
\hline \multirow[b]{2}{*}{ Characteristics } & \multicolumn{4}{|c|}{ Age groups, $n(\%)^{a}$} \\
\hline & $\begin{array}{c}0-3 \text { mos } \\
n=25\end{array}$ & $\begin{array}{c}4 \text { mos - } \\
9 \text { yrs } \\
n=63\end{array}$ & $\begin{array}{c}10-18 \\
\text { yrs } \\
n=56\end{array}$ & $\begin{array}{l}\text { Total } \\
n=144\end{array}$ \\
\hline \multicolumn{5}{|l|}{ Clinical presentation } \\
\hline Paroxysmal cough & $20(80.0)$ & $47(74.6)$ & $34(60.7)$ & $101(70.1)$ \\
\hline Inspiratory whoop & $9(36.0)$ & $7(11.1)$ & $4(7.1)$ & 20 (13.9) \\
\hline Post-tussive emesis & $10(40.0)$ & $32(50.8)$ & $26(46.4)$ & $68(47.2)$ \\
\hline Cyanosis & $15(60.0)$ & $4(6.3)$ & $1(1.8)$ & $20(13.9)$ \\
\hline Chest retractions & $10(40.0)$ & $3(4.8)$ & $0(0.0)$ & $13(9.0)$ \\
\hline Fever & $2(8.0)$ & $10(15.9)$ & $4(7.1)$ & $16(11.1)$ \\
\hline Coryza & $14(56.0)$ & $20(31.8)$ & $14(25.0)$ & $48(33.3)$ \\
\hline $\begin{array}{l}\text { Pulmonary signs on } \\
\text { exam }\end{array}$ & $8(32.0)$ & $8(12.7)$ & $2(3.6)$ & $18(12.5)$ \\
\hline Apnea & $10(40.0)$ & $0(0.0)$ & $0(0.0)$ & $10(6.9)$ \\
\hline Otitis & $2(8.0)$ & $6(9.5)$ & $2(3.6)$ & $10(6.9)$ \\
\hline Pharyngitis & $2(8.0)$ & $2(3.2)$ & $7(12.5)$ & $11(7.6)$ \\
\hline $\begin{array}{l}\text { Sub-conjunctival } \\
\text { hemorrhage }\end{array}$ & $0(0.0)$ & $1(1.6)$ & $0(0.0)$ & $1(0.7)$ \\
\hline Seizures & $0(0.0)$ & $0(0.0)$ & $0(0.0)$ & $0(0.0)$ \\
\hline \multicolumn{5}{|l|}{ MPS } \\
\hline Average & 11.8 & 4.7 & 3.3 & 5.4 \\
\hline Median & 12 & 5 & 3 & 5 \\
\hline - IQR 25-75 & 9-15 & $3-6$ & $2-5$ & IQR 3-7 \\
\hline $\begin{array}{l}\text { Severe cases } \\
\text { (MPS } \geq 7 \text { ) }\end{array}$ & $21(84.0)$ & $12(22.2)$ & $2(3.6)$ & $37(25.7)$ \\
\hline \multicolumn{5}{|l|}{ Paraclinical tests } \\
\hline $\begin{array}{l}\text { Viral multiplex } \\
\text { done }\end{array}$ & $13(52.0)$ & $6(9.5)$ & $5(8.9)$ & $24(16.7)$ \\
\hline $\begin{array}{l}\text { - Respiratory } \\
\text { virus found }\end{array}$ & $5(38.5)$ & $2(33.3)$ & $1(20.0)$ & $8(33.3)$ \\
\hline $\begin{array}{l}\text { Complete blood } \\
\text { count done }\end{array}$ & $21(84.0)$ & $10(15.9)$ & $3(5.4)$ & $34(23.6)$ \\
\hline - Lymphocytosis ${ }^{\mathrm{b}}$ & $10(47.7)$ & $3(30.0)$ & $0(0.0)$ & $13(38.2)$ \\
\hline Chest x-ray done & $20(80.0)$ & $43(68.3)$ & $37(66.1)$ & $100(69.4)$ \\
\hline 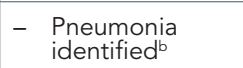 & $0(0.0)$ & $6(14.0)$ & $2(5.4)$ & $8(8.0)$ \\
\hline
\end{tabular}

Children four months to nine years of age were also significantly affected: $22.2 \%$ had severe pertussis. In comparison, only two (3.6\%) children older than 10 years of age had severe pertussis. Inter-rater agreement using kappa statistics was 0.86 , showing good validity of data collection.

\section{Outcomes}

Overall, $20.8 \%$ of patients were hospitalized (Table 3 ). Infants less than three months of age had the highest risk of hospitalization (92\%) with a significant proportion (28\%) requiring 
intensive care admission. In comparison, $11 \%$ of children four months to nine years of age and none of older children were hospitalized. The majority of patients $(75.2 \%)$ were treated with macrolides. There were no deaths.

\section{Table 3: Outcomes of children with PCR-confirmed} pertussis

\begin{tabular}{|c|c|c|c|c|}
\hline \multirow[b]{2}{*}{ Outcomes } & \multicolumn{4}{|c|}{ Age groups, $n(\%)^{a}$} \\
\hline & $\begin{array}{l}0-3 \\
\text { mos } \\
n=25\end{array}$ & $\begin{array}{c}4 \text { mos - } \\
9 \text { yrs } \\
n=63\end{array}$ & $\begin{array}{c}10-18 \\
y r s \\
n=56\end{array}$ & $\begin{array}{l}\text { Total } \\
n=144\end{array}$ \\
\hline Hospitalization & $23(92.0)$ & $7(11.1)$ & $0(0.0)$ & $30(20.8)$ \\
\hline \multicolumn{5}{|l|}{ Length of stay } \\
\hline Average, days & 11.0 & 3.0 & 0.0 & 9.1 \\
\hline Median & 8 & 3 & 0 & 5 \\
\hline - IQR 25-75 & $3-14$ & $2-4$ & 0 & $3-12$ \\
\hline Intensive care & $7(28.0)$ & $0(0.0)$ & $0(0.0)$ & $7(4.9)$ \\
\hline Death & $0(0.0)$ & $0(0.0)$ & $0(0.0)$ & $0(0.0)$ \\
\hline Received macrolide & $18(72.0)$ & $46(73.0)$ & $45(80.4)$ & $109(75.7)$ \\
\hline
\end{tabular}

Abbreviations: IQR, interquartile range; mos, months; $n$, number; yrs, years

All results reported as $n$ (\%) with the exception of Length of stay which is average (in days) and Median with IQR

\section{Discussion}

This study draws a brief portrait of the clinical presentation and outcomes of patients with pertussis presenting to a tertiary care pediatric hospital. Despite the introduction of a universal acellular pertussis immunization program in Quebec, infants less than three months of age are still affected by pertussis. Most suffered a severe disease (84\%) and required hospitalization (92\%), including in the intensive care unit (28\%), for a median length of stay of eight days, similar to previous studies $(10,18,21,25-31)$. Disease was milder in older children, as shown by lower MPS scores and hospitalization rates. Only a minority of children had severe pertussis, with no hospitalization in those 10 years or older, suggesting that older children, like adults, were less severely affected by this infection $(25,32)$.

Overall, symptoms suggestive of pertussis, such as paroxysmal cough, inspiratory whoop and post-tussive emesis, were found in a large proportion of children of all ages, but less frequently than what was previously reported $(25,29,31)$. For example, in previous studies children age nine years or younger, paroxysmal cough, inspiratory whoop and post-tussive emesis were previously reported in 89-93\% (cough), 69-92\% (whoop) and $48-60 \%$ (emesis) of children. In contrast, in our study these symptoms were present in $76 \%$ (cough), 25\% (whoop) and $48 \%$ (emesis) of children of similar age. These differences could be due in part to an attenuation of disease following immunization, but could also be the result of the increased sensitivity of PCR compared with culture, which allows for detection of less symptomatic cases (33). It was previously shown that immunity and protection provided by the acellular vaccine wanes rapidly,
(9), which may explain the high proportion of positive tests in children $10-15$ years of age (25-40\%).

This study offers a description of pediatric cases of pertussis in Quebec. There are several limitations to consider. First, this study was from a single centre; nevertheless, the 144 cases analyzed in this study represented approximately $12.4 \%$ of all pertussis cases $<18$ years of age diagnosed in the province of Quebec during the study period (8). Second, there was the risk of information bias, including potential misclassification of the vaccination status, an intrinsic risk associated with chart review. We tried to minimize the risk by documenting a high inter-rater agreement. Third, we analyzed only patients who sought medical attention in a hospital setting, which may overestimate the severity of disease. However, this bias is probably not significant in infants less than three months of age, as reported cases of pertussis in this age group usually seek emergency care and are hospitalized (34). Finally, the study period included the peak of a four-year epidemic cycle (2016), which could have led to a slight overestimation of the incidence of pertussis.

In terms of next steps and future research, this study could provide a baseline for a future evaluation of the impact of the vaccination of pregnant women on the pertussis disease burden in young children.

\section{Conclusion}

Pertussis still affects children of all ages in Quebec. In older children it tends to be a milder disease. When it affects infants, who do not yet have full protection from pertussis vaccination, it often causes severe disease, especially in those less than three months of age. This evidence further supports the implementation of a pertussis vaccination program in pregnant women and provides a baseline to assess the impact of this program.

\section{Authors' statement}

$\mathrm{MD}^{\dagger}$ - conceptualization, methodology, validation, investigation, data curation, writing of original draft, review and editing of final version

$\mathrm{DI}^{\dagger}$ - conceptualization, methodology, validation, formal analysis, investigation, data curation, writing of original draft, review and editing of final version

SM - methodology, review and editing of final version PDP - formal analysis, review and editing of final version NB - methodology, review and editing of final version FR - Investigation, resources, review and editing of final version $\mathrm{CQ}$ - conceptualization, methodology, review and editing of final version, supervision, funding acquisition

† Both MD and DI contributed equally to the work. 


\section{COHORT STUDY}

\section{Conflict of interest}

None.

\section{Funding}

Dr. Quach is supported through an external salary award (FRQ-S merit, grant \# 252775). This research was supported by the CHU Sainte-Justine Research Institute (C. Quach's start-up funds).

\section{References}

1. Bennett JE, Dolin R, Blaser MJ. Mandell, Douglas, and Bennett's Principles and Practice of Infectious Diseases. 8th Edition. Elsevier, 2014.

2. Gabutti G, Azzari C, Bonanni P, Prato R, Tozzi AE, Zanetti A, Zuccotti G. Pertussis. Hum Vaccin Immunother 2015;11(1):108-17. https://doi.org/10.4161/hv.34364. PubMed (https://www.ncbi.nlm. nih.gov/pubmed/25483523?dopt=Abstract)

3. Health and Welfare Canada. National Advisory Committee on Immunization. A Guide to Immunization for Canadians. Dixon JMS, editor. Ottawa ON: Supply and Services Canada; 1980.

4. Smith T, Rotondo J, Desai S, Deehan H. Pertussis surveillance in Canada: trends to 2012. Can Commun Dis Rep 2014 Feb;40(3):21-30. PubMed (https://www.ncbi.nlm.nih.gov/ pubmed/29769879?dopt=Abstract)

5. Douville-Fradet M, Amini R. Épidémiologie descriptive des maladies à déclaration obligatoire évitables par la vaccination au Québec, 2011-2013. Québec, Canada: Insitut National de Santé Publique; 2016.

6. Brousseau N, Judd L, Marcoux-Huard C, Landry M. Guide d'intervention - La coqueluche, mise à jour octobre 2016. Québec, Canada: MSSS; 2016. www.inspq.qc.ca/sites/default/files/ publications/2198_maladies_evitables_vaccination_declaration_ obligatoire.pdf

7. Kiely M, Boulianne N, Ouakki M, Audet D, Gariépy MC, Guay $M$, De Serres G, Dubé E. Enquête sur la couverture vaccinale des enfants de 1 an et 2 ans au Québec en 2016. Québec Canada: INSPQ; 2017. www.inspq.qc.ca/sites/default/files/ publications/2341_enquete_couverture_vaccinale_enfants_2016. pdf

8. Ministère de la santé et des services sociaux du Québec. Vigie et surveillance des maladies à déclaration obligatoire d'origine infectieuse Québec: MSSS; 2017. http://publications.msss.gouv. qc.ca/msss/fichiers/2017/17-268-05W.pdf

9. Schwartz KL, Kwong JC, Deeks SL, Campitelli MA, Jamieson FB, Marchand-Austin A, Stukel TA, Rosella L, Daneman N, Bolotin S, Drews SJ, Rilkoff H, Crowcroft NS. Effectiveness of pertussis vaccination and duration of immunity. CMAJ 2016 Nov;188(16):E399-406. https://doi.org/10.1503/cmaj.160193. PubMed (https://www.ncbi.nlm.nih.gov/pmc/articles/ PMC5088088/)

10. Heininger $U$, Weibel $D$, Richard JL. Prospective nationwide surveillance of hospitalizations due to pertussis in children, 20062010. Pediatr Infect Dis J 2014 Feb;33(2):147-51. https://doi. org/10.1097/01.inf.0000435503.44620.74. PubMed (https://www. ncbi.nlm.nih.gov/pubmed/24413406?dopt=Abstract)

11. Hviid A, Stellfeld M, Andersen PH, Wohlfahrt J, Melbye M. Impact of routine vaccination with a pertussis toxoid vaccine in Denmark. Vaccine 2004 Sep;22(27-28):3530-4. https://doi.org/10.1016/j. vaccine.2004.03.046. PubMed (https://www.ncbi.nlm.nih.gov/ pubmed/15315832?dopt=Abstract)

12. Gall SA, Myers J, Pichichero M. Maternal immunization with tetanus-diphtheria-pertussis vaccine: effect on maternal and neonatal serum antibody levels. Am J Obstet Gynecol 2011 Apr;204(4):334.e1-5. https://doi.org/10.1016/j. ajog.2010.11.024. PubMed (https://www.ncbi.nlm.nih.gov/ pubmed/21272845?dopt=Abstract)

13. Abu Raya B, Srugo I, Kessel A, Peterman M, Bader D, Gonen R, Bamberger $\mathrm{E}$. The effect of timing of maternal tetanus, diphtheria, and acellular pertussis (Tdap) immunization during pregnancy on newborn pertussis antibody levels - a prospective study. Vaccine 2014 Oct;32(44):5787-93. https://doi.org/10.1016/j. vaccine.2014.08.038. PubMed (https://www.ncbi.nlm.nih.gov/ pubmed/25173476?dopt=Abstract)

14. Baxter R, Bartlett J, Fireman B, Lewis E, Klein NP. Effectiveness of Vaccination During Pregnancy to Prevent Infant Pertussis. Pediatrics 2017 May;139(5):e20164091. https://doi.org/10.1542/ peds.2016-4091. PubMed (https://www.ncbi.nlm.nih.gov/ pubmed/28557752?dopt=Abstract)

15. National Advisory Committee on Immunization. Update on Immunization in Pregnancy with Tdap Vaccine. Canada: Public Health Agency of Canada; 2018. www.canada.ca/en/publichealth/services/publications/healthy-living/update-immunizationpregnancy-tdap-vaccine.html

16. Comité sur l'immunisation du Québec $(\mathrm{ClQ})$. Avis sur la pertinence de mettre en place la vaccination contre la coqueluche chez toutes les femmes enceintes au Québec. Québec: Institut national de santé publique du Québec; 2016 www.inspq.qc.ca/ publications/2089

17. Halperin $S A$, Wang EE, Law $B$, Mills $E$, Morris R, Déry P, Lebel M, MacDonald N, Jadavji T, Vaudry W, Scheifele D, Delage G, Duclos P. Epidemiological features of pertussis in hospitalized patients in Canada, 1991-1997: report of the Immunization Monitoring Program--Active (IMPACT). Clin Infect Dis 1999 Jun;28(6):1238-43. https://doi.org/10.1086/514792. PubMed (https://www.ncbi.nlm. nih.gov/pubmed/10451159?dopt=Abstract)

18. Bettinger JA, Halperin SA, De Serres G, Scheifele DW, Tam T. The effect of changing from whole-cell to acellular pertussis vaccine on the epidemiology of hospitalized children with pertussis in Canada. Pediatr Infect Dis J 2007 Jan;26(1):31-5. https://doi. org/10.1097/01.inf.0000247055.81541.04. PubMed (https://www. ncbi.nlm.nih.gov/pubmed/17195702?dopt=Abstract)

19. Direction des communications du CHU Sainte-Justine. Rapport annuel CHU Sainte-Justine 2016-2017. Montréal: CHU Sainte-Justine; 2017. www.chusj.org/CORPO/files/3c/3cb7bfb502e6-4629-866e-5f9f3a815566.pdf

20. Liko J, Robison SG, Cieslak PR. Do Pertussis Vaccines Protect Against Bordetella parapertussis? Clin Infect Dis 2017 Jun;64(12):1795-7. https://doi.org/10.1093/cid/cix221. PubMed (https://www.ncbi.nlm.nih.gov/pubmed/28369240?dopt=Abstract)

21. Cherry JD, Tan T, Wirsing von König CH, Forsyth KD, Thisyakorn U, Greenberg D, Johnson D, Marchant C, Plotkin S. Clinical definitions of pertussis: Summary of a Global Pertussis Initiative roundtable meeting, February 2011. Clin Infect Dis 2012 Jun;54(12):1756-64. https://doi.org/10.1093/cid/cis302. PubMed (https://www.ncbi.nlm.nih.gov/pubmed/22431797?dopt=Abstract)

22. Gill CJ, Mwananyanda L, MacLeod W, Kwenda G, Mwale M, Williams AL, Siazeele K, Yang Z, Mwansa J, Thea DM. Incidence of Severe and Nonsevere Pertussis Among HIV-Exposed and -Unexposed Zambian Infants Through 14 Weeks of Age: Results From the Southern Africa Mother Infant Pertussis Study (SAMIPS), a Longitudinal Birth Cohort Study. Clin Infect Dis 2016 Dec;63(suppl 4):S154-64. https://doi.org/10.1093/cid/ciw526. PubMed (https:// www.ncbi.nlm.nih.gov/pubmed/27838668?dopt=Abstract)

23. Omer SB, Kazi AM, Bednarczyk RA, Allen KE, Quinn CP, Aziz F, Sial K, Phadke VK, Tondella ML, Williams MM, Orenstein WA, Ali SA. Epidemiology of Pertussis Among Young Pakistani Infants: A Community-Based Prospective Surveillance Study. Clin Infect Dis 2016 Dec;63 suppl 4:S148-53. https://doi. 
org/10.1093/cid/ciw561. PubMed (https://www.ncbi.nlm.nih.gov/ pubmed/27838667?dopt=Abstract)

24. Soofie N, Nunes MC, Kgagudi P, van Niekerk N, Makgobo T, Agosti Y, Hwinya C, Pathirana J, Madhi SA. The Burden of Pertussis Hospitalization in HIV-Exposed and HIV-Unexposed South African Infants. Clin Infect Dis 2016 Dec;63 suppl 4:S165-73. https://doi. org/10.1093/cid/ciw545. PubMed (https://www.ncbi.nlm.nih.gov/ pubmed/27838669?dopt=Abstract)

25. Kilgore PE, Salim AM, Zervos MJ, Schmitt HJ. Pertussis: Microbiology, Disease, Treatment, and Prevention. Clin Microbiol Rev 2016 Jul;29(3):449-86. https://doi.org/10.1128/ CMR.00083-15. PubMed (https://www.ncbi.nlm.nih.gov/ pubmed/27029594?dopt=Abstract)

26. Del Valle-Mendoza J, Casabona-Oré V, Petrozzi-Helasvuo V, Cornejo-Tapia A, Weilg P, Pons MJ, Cieza-Mora E, Bazán-Mayra $\mathrm{J}$, Cornejo-Pacherres H, Ruiz J. Bordetella pertussis diagnosis in children under five years of age in the Regional Hospital of Cajamarca, Northern Peru. J Infect Dev Ctries 2015 Nov;9(11):1180-5. https://doi.org/10.3855/jidc.6803. PubMed (https://www.ncbi.nlm.nih.gov/pubmed/26623626?dopt=Abstract)

27. Masseria C, Martin CK, Krishnarajah G, Becker LK, Buikema A, Tan TQ. Incidence and Burden of Pertussis Among Infants Less Than 1 Year of Age. Pediatr Infect Dis J 2017 Mar;36(3):e54-61. https:// doi.org/10.1097/INF.0000000000001440. PubMed (https://www. ncbi.nlm.nih.gov/pubmed/27902648?dopt=Abstract)

28. Kaczmarek MC, Ware RS, McEniery JA, Coulthard MG, Lambert SB. Epidemiology of pertussis-related paediatric intensive care unit (ICU) admissions in Australia, 1997-2013: an observational study. BMJ Open 2016 Apr;6(4):e010386. https://doi.org/10.1136/ bmjopen-2015-010386. PubMed (https://www.ncbi.nlm.nih.gov/ pubmed/27053270?dopt=Abstract)
29. Carlsson RM, von Segebaden K, Bergstrom J, Kling AM, Nilsson L. Surveillance of infant pertussis in Sweden 1998-2012; severity of disease in relation to the national vaccination programme. Euro Surveill 2015 Feb;20(6):21032. https://doi.org/10.2807/1560-7917 ES2015.20.6.21032. PubMed (https://www.ncbi.nlm.nih.gov/ pubmed/25695476?dopt=Abstract)

30. Cortese MM, Baughman AL, Zhang R, Srivastava PU, Wallace GS. Pertussis hospitalizations among infants in the United States, 1993 to 2004. Pediatrics 2008 Mar;121(3):484-92. https://doi. org/10.1542/peds.2007-1393. PubMed (https://www.ncbi.nlm.nih. gov/pubmed/18310196?dopt=Abstract)

31. Gentile A, Romanin VS, Juárez MV, Lución MF, Marques ML, Mistchenko AS. Epidemiology of Bordetella pertussis in a children's hospital. Arch Argent Pediatr 2014 Feb;112(1):26-32. https://doi.org/10.1590/S0325-00752014000100006. PubMed (https://www.ncbi.nlm.nih.gov/pubmed/24566778?dopt=Abstract)

32. Kline JM, Lewis WD, Smith EA, Tracy LR, Moerschel SK. Pertussis: a reemerging infection. Am Fam Physician 2013 Oct;88(8):507-14. PubMed (https://www.ncbi.nlm.nih.gov/ pubmed/24364571?dopt=Abstract)

33. Kaczmarek MC, Ware RS, Lambert SB. The contribution of PCR testing to influenza and pertussis notifications in Australia. Epidemiol Infect 2016 Jan;144(2):306-14. https://doi.org/10.1017/ S0950268815001004. PubMed (https://www.ncbi.nlm.nih.gov/ pubmed/26112983?dopt=Abstract)

34. Winter K, Cherry JD, Harriman K. Effectiveness of Prenatal Tetanus, Diphtheria, and Acellular Pertussis Vaccination on Pertussis Severity in Infants. Clin Infect Dis 2017 Jan;64(1):9-14. https://doi. org/10.1093/cid/ciw633. PubMed (https://www.ncbi.nlm.nih.gov/ pubmed/27624956?dopt=Abstract)
Pertussis vaccine immunity wanes over time

Pertussis, or whooping cough, is a respiratory tract infection that can be prevented with vaccination.

\section{PROTECTION}

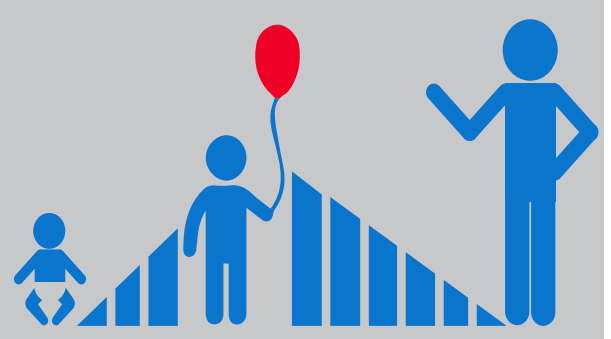

However, protection takes several shots to establish and then protection wanes over time.

\section{Young infants are most at} risk

Infants less than three months of age have only received one dose of the vaccine.
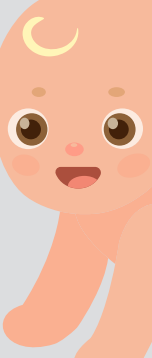

Infants get the most sick

A recent study found most infants less than three months with pertussis had severe disease and of those ${ }^{1}$ :

- $92 \%$ required hospitalization

- $28 \%$ intensive care admission

\section{How to prevent infection}

Make sure you and your family are up to date with your vaccines ${ }^{2}$ :

\section{ROUTINE CHILDHOOD IMMUNIZATION SCHEDULE 2, 4, 6, 12-23 months and $4-6$ years \\ 2. ADOLESCENT BOOSTER at $14-16$ years}

\section{ADULT BOOSTER}

4. WITH EVERY PREGNANCY

Protective antibodies are transferred to the baby Best between 27-32 weeks

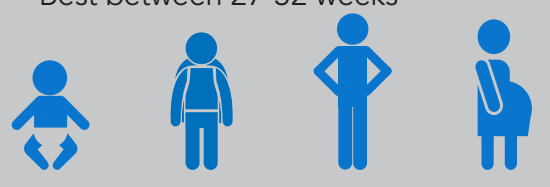

Desjardins M, lachimov D, Mousseau S, Doyon-Plourde P, Brousseau N, Rallu F, Quach C. Clinical characteristics of pediatric pertussis cases, Quebec 2015-2017. Can Commun Dis Rep 2018:44 (9):190-195. ${ }^{2}$ National Advisory Committee on Immunization (NACl). Pertussis vaccine. Part 4: Canadian Immunization Guide March 2018. Ottawa: Public Health Agency of Canada. https://www.canada.ca/en/public-health/services/publications/healthy-2 National Advisory Committee on Immunization (NACl). Pertussis vaccine. Part 4: Canadian Im 